Freihandelsabkommen und Globalisierung

\section{Perspektivlose Handelspolitik}

Die gegenwärtige Handelspolitik der Europäischen Union ist geprägt von dem Ziel weiterer Marktöffnung. Um der fortschreitenden Globalisierung zu begegnen, braucht es vielmehr eine neue Balance zwischen globalen und regionalen Märkten. Von Jürgen Maier

W er geglaubt - oder gehofft - hatte, dass es nach dem Scheitern des Transatlantischen Freihandelsabkommens (TTIP) und dem Beinahe-Scheitern des Wirtschafts- und Handelsabkommens mit Kanada (CETA) wieder ruhiger um die Handelspolitik der EU werden würde, wird zurzeit eines Besseren belehrt.

Nach dem spektakulären Fiasko des G7-Gipfels kam es wenige Tage noch dicker, wenn auch ohne entsprechendes internationales Presseecho. Italiens neue Regierung kündigte an, den CETA-Vertrag nicht zu ratifizieren. Im Koalitionsvertrag hatte man in Rom sogar festgelegt, künftig alle geplanten derartigen „Freihandelsabkommen“ der EU abzulehnen. Ein amtliches Nein aus Rom würde den in der "vorläufigen Anwendung" befindlichen CETA-Vertrag gegenstandslos machen.

Etwa 20 weitere „Freihandelsabkommen" hat die EU noch in der Pipeline. Alle folgen sie im wesentlichem demselben Strickmuster, geprägt vom Geist der neoliberalen Globalisierung: weitere Marktöffnung im Agrar- und Dienstleistungssektor, Beseitigung sogenannter "nichttarifärer Handelshemmnisse" durch generelle Erschwerung von Regulierung, Kommerzialisierung der öffentlichen Daseinsvorsorge, Ausweitung von Investitionsschutz. Eine Agenda, wie sie vor allem dem Exportweltmeister Deutschland nützt, von der aber andere EU-Staaten weniger profitieren. Vor allem aber ist es genau die Art von Globalisierung, die selbst nach den Analysen des Weltwirtschaftsforums $\mathrm{zu}$ wenige Gewinner/innen und zu viele Verlierer/ innen hat, zu wenig Nachhaltigkeit und zu viel Ungleichheit erzeugt.

Mit dem Schachzug, nach dem Beinahe-Scheitern des CETA-Vertrags solche Abkommen nicht mehr als "gemischte Abkommen " in der gemeinsamen $\mathrm{Zu}$ ständigkeit von EU und Mitgliedsstaaten, sondern künftig in der Alleinzuständigkeit der EU abzuschließen, glaubte man sich auf der sicheren Seite. Nur noch EU-Parlament und EU-Rat müssen ratifizieren, das Risiko ist überschaubar.

\section{Neustart in der Wirtschafts- politik?}

Nun wird aber immer offensichtlicher, dass es im Ernstfall nur ein entschlossenes Nein eines einzigen Akteurs braucht, um solche Abkommen platzen zu lassen, und die Popularität solche Akteure dadurch sogar steigt. Damit ist eine Handelspolitik, eine Globalisierungspolitik in ihren Grundfesten erschüttert, die bis vor Kurzem noch als globaler Konsens galt. Sie entpuppt sich nun als Kartenhaus.

Das deutsche Geschäftsmodell „Exportweltmeister" stößt offensichtlich an seine Grenzen: Exportstärke ist eben auch Exportabhängigkeit und damit Verwundbarkeit. Wie jede Abhängigkeit hat sie auch eine Menge Schattenseiten. Mit 48\% Exportanteil am Bruttoinlandsprodukt steht Deutschland allein auf weiter Flur, kein anderes Industrieland kommt auch nur annähernd auf solche Werte.
Wir brauchen einen Neustart in der Wirtschaftspolitik. Es geht nicht um Protektionismus oder Freihandel, es geht um eine neue Balance zwischen globalen und regionalen Märkten und eine neue Balance zwischen Prioritäten in der Handelspolitik. Es geht um eine Neuauflage einer sozialen und ökologischen Marktwirtschaft statt der Exzesse des "Shareholder-Value-Neoliberalismus“. Dafür braucht man auch eine andere Handelspolitik - und zwar weder exzessive Globalisierung noch protektionistischen Wirtschaftsnationalismus und "Handelskriege“. Dabei muss es auch Mechanismen gegen exzessive Überschüsse und Defizite, ebenso gegen Umwelt- und Sozialdumping geben. Wer es mit der Wettbewerbsfähigkeit übertreibt, muss gebremst werden.

Wer das blockiert, bekommt noch mehr Wahlsiege von Leuten wie Trump. Genau das passiert zurzeit. Machen wir uns nichts vor: Eine Reform der Welthandelsorganisations-Verträge (WTO) oder anderer Freihandelsabkommen ist nicht in Sicht, die kann nur im Konsens beschlossen werden. Wahrscheinlicher ist daher eine weitere Erosion eines Vertragssystems, von dem immer mehr Akteure glauben, dass es sie benachteiligt. $\mathrm{Ob}$ sie das zu Recht glauben oder nicht, spielt dabei keine Rolle. Die verzweifelten Versuche der EU-Kommission und der Bundesregierung, mit den 20 geplanten weiteren Freihandelsabkommen einfach so weiterzumachen, werden das eher noch verschärfen. Auch diese Verträge werden im Ernstfall immer öfter einfach ignoriert werden, wenn sie überhaupt zustande kommen.

Das internationale System steht vor einer langen Phase anhaltender Unsicherheit. Wer es mit Weiter-So probiert wie die EU-Kommission, wird scheitern.

AUTOR + KONTAKT

Jürgen Maier ist Geschäftsführer des Forums Umwelt \& Entwicklung.

Forum Umwelt \& Entwicklung, Marienstr. 19-20, 10117 Berlin. Tel.: +4930678177588 E-Mail: info@forumue.de 